\title{
Correlation between induration diameter of skin prick test result to house dust mite allergen with immunotherapy efficacy
}

\author{
Dian Yashifa ${ }^{\mathrm{a}, \mathrm{b} *}$, Anang Endaryanto ${ }^{\mathrm{a}, \mathrm{b}}$, and Retno Asih Setyaningrum ${ }^{\mathrm{a}, \mathrm{b}}$

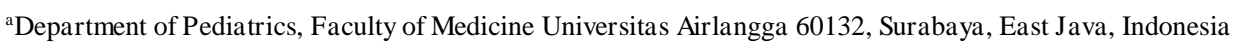 \\ bDr. Soetomo General Hospital, 60286, Surabaya, East Java, Indonesia
}

\begin{abstract}
Background: House dust mite (HDM) is one of the most aeroallergen causing allergy disease. Skin prick test (SPT) is simple test for hypersensitivity related IgE. Positivity of house dust mite skin prick test result is essential to start immunotherapy.

Objective: This study aimed to investigate the correlation between induration diameter of skin prick test result to house dust mite allergen with immunotherapy efficacy.

Methods: This retrospective study was conducted in Pediatric allergy and immunology outpatient clinic of Dr. Soetomo General Hospital Surabaya. Medical record was taken from January 1st until December 31st 2020 period. House dust mite allergy was diagnosed based on positivity of skin prick test to HDM. Immunotherapy efficacy was evaluated with daily symptom score (dSS), daily medication score (dMS), and Combined Symptom and Medication Score (CSMS) at least 3 months after immunotherapy. Age, gender, duration of illness, nutritional status, family history of atopic allergic disease, and other allergic comorbidities were stipulated as confounding variable. Statistical analysis were normality distribution test, wilcoxon rank test, spearman test, and regression analysis.

Results: Sixty patient of HDM allergy (33 boys and 27 girls), were included in this study. Significant alteration of dSS, $\mathrm{dMS}$, and CSMS before and after immunotherapy evaluated with wilcoxon rank test result ( $\mathrm{p}=0.000$ respectively). There was no correlation of each confounding variables to induration diameter of SPT. Positive correlation between induration diameter and CSMS score was tested with Spearman test $(\mathrm{p}=0.003, \mathrm{r}=0.373)$.
\end{abstract}

Conclusions: Smaller induration diameter of HDM SPT result could be predictive for immunotherapy efficacy.

Keywords: House dust mite; skin prick test; induration diameter; immunotherapy; symptom score; medication score.

\section{Introduction}

House Dust Mite (HDM) is one of the main aeroallergens that manifest allergic manifestations in the world (Calderón et al., 2015). Skin prick test has high specificity and sensitivity, 70-95\% and 80-97\%, for diagnosing allergy due to inhaled substances. Nail test is the most effective diagnostic test for detecting immunoglobulin E-mediated type I hypersensitivity reactions (Bousquet et al., 2019). The skin prick test is cost-efficient and has a good adaptability to determine allergen status in children (Zhong et al., 2014). The size of the induration diameter from the skin prick test results to house dust allergens can be influenced by many factors (Rengganis, 2018). The skin prick test results for house dust mite allergens are significantly positive as a guide for patients to avoid associated allergens, and are a definite basis for specific immunotherapy (Rasool et al., 2013). Allergenspecific immunotherapy is able to address the root cause of allergic diseases, unlike symptomatic treatment which only controls symptoms (Endaryanto, 2019). One of the assessments of the effectiveness of 
immunotherapy is carried out using a quantitative score on symptoms and use of drugs, as well as a combination of the two (Frew et al., 2018).

It is estimated that around 30-40\% of the world's population has one or more allergic diseases (Rengganis, 2018). House dust mites induce sensitization in $77 \%$ of asthmatic patients (Moustaki et al., 2017). The house dust mite sensitization rate in China, Taipei, Indonesia, and Korea reaches $80-90 \%$ in patients with respiratory allergy symptoms (Tham et al., 2016). Although data are limited, the efficacy of allergen-specific immunotherapy against childhood asthma in Surabaya has been reported in a small number of experimental studies (Endaryanto, 2020). The decision to use antigen-specific immunotherapy in house dust mite allergy patients requires a careful study of the patient's condition and the role of allergy triggers (Endaryanto, 2019). Antigen-specific immunotherapy aims to achieve clinical tolerance to the causative allergen through the administration of an allergen-specific extract. Allergens are given periodically as a natural exposure with the quantity increased to the effective dose limit for sensitization. The World Health Organization (WHO) states that antigen-specific immunotherapy is a form of therapy that can modify the natural course of allergic diseases. This therapy is effective in the treatment of IgE-mediated type I allergic disease, by relieving symptoms of allergic rhinitis and/or asthma, reducing the use of medication for symptom relief, and improving the patient's quality of life. Immunotherapy has also shown long-term effects, even after discontinuation of therapy, reducing the risk of new allergen sensitization, and preventing the development of asthma in individuals with allergic diseases (Yang and Zhu, 2017).

Skin prick test that is negative for house dust mite (Dermatophagoides pteronyssinus) has a negative predictive value of $90-95 \%$ in adults. While the positive predictive value ranged from $29-43 \%$ in older subjects and $77-100 \%$ in younger subjects (Heinzerling et al., 2013). Skin prick testing is recommended for the diagnosis of intermediate-type allergies because there is a strong correlation between symptoms and provocative testing as recommended by studies by the European Academy of Allergology and Clinical Immunology (EAACI), WHO, and The US Joint Council of Allergy Asthma and Immunology. There is some supporting data regarding the relationship between skin prick testing and the efficacy of allergy-specific immunotherapy. In a study of 26 study subjects aged 23-42 years with allergic rhinitis in Istanbul, Turkey, who received subcutaneous immunotherapy, there was a significantly lower change in symptom scores after 3 years of follow-up ( $p=$ 0.0175). The effectiveness of immunotherapy in this study was assessed based on the induration diameter of the skin prick test results against house dust mites (Dermatophagoides pteronysinnus and Dermatophagoides farinae) and symptom scores before and after subcutaneous immunotherapy 3 years and 10 years, and the results showed statistically significant changes (Sahin et al., 2017). In patients with uncontrolled asthma, a larger induration diameter was found on the skin prick test, indicating that this variable can predict clinical outcomes in patients receiving subcutaneous immunotherapy (Cheng et al., 2018). This is corroborated by a retrospective cohort study in Indonesia in 2019, the results showed that there was a change in the induration diameter for the skin prick test (house dust mite allergens: Dermatophagoides pteronyssinus (Der p 1) and Dermatophagoides farinae (Der f 1) to become smaller after subcutaneous immunotherapy. for 3 months, in $73.8 \%$ of children with allergic asthma (Endaryanto, 2019).

Despite the safety and success of immunotherapy, not all patients respond and experience clinical improvement. The recommended allergen-specific immunotherapy therapy for allergic rhinitis is 3-5 years and the average success rate ranges from $52-86.4 \%$ with varying definitions of immunotherapy success (Di Lorenzo et al., 2009; Erekosima et al., 2014; Shin et al., 2019). Prediction of the response to immunotherapy in the second year can be done at month 4 of treatment, through symptom scores and treatment to determine the need for longterm therapy (Liu et al., 2020). Initial evaluation of the effectiveness of subcutaneous immunotherapy was carried out after the build-up phase because it was considered as important data for patient education programs to improve adherence and therapeutic outcomes (Endaryanto, 2019). A skin prick test is an examination that causes little discomfort in pediatric patients, so repeat evaluation using a skin prick test only to determine the 
effectiveness of immunotherapy is not the main choice. This study is the first study to assess the relationship between the induration diameter of the skin prick test before starting immunotherapy and the clinical outcome of the effectiveness of the immunotherapy that will be undertaken.

\section{Material and Methods}

This study was an observational analytic study with a retrospective cohort study design in children who received subcutaneous allergen-specific immunotherapy after the first 3 months (late initial phase). The data were then completed cross-sectionally to complete the data for confounding variables. The study was conducted in Surabaya using secondary data in the form of medical records from the pediatric allergy-immunology outpatient clinic, Dr. Soetomo General Hospital Surabaya. Data collection was carried out from February-April 2021.

The sample of this study was data from all pediatric patients who underwent skin prick tests which were recorded in the allergy poly register book at Dr. Soetomo General Hospital who met the inclusion and exclusion criteria of the study. The diagnosis of allergy due to house dust mites is made based on a typical history of allergic symptoms and a positive skin prick test result for house dust mites (Bousquet et al., 2019). The research ethics suitability was submitted and obtained from the Health Research Ethics Committee (KPEK) Dr. Soetomo General Hospital Surabaya. This research was started after obtaining permission and approval from KPEK Dr. Soetomo General Hospital Surabaya with ethics certificate number: 0365/LOE/301.4.2/II/2021. Confidentiality of research subjects is well maintained (names are replaced with initials). The research data are only used for research purposes.

\subsection{Statistical Analysis}

The research data will be analyzed using statistical tests using the SPSS device. The basic characteristics of the research subjects will be presented descriptively in tabular form. Bivariate analysis was performed on several confounding variables such as age, gender, length of illness, number of nuclear families with allergies, and other allergy comorbidities. If there is a p-value $<0.25$, then the multivariate analysis is carried out. The test carried out between the independent and dependent variables is a correlation test of two numerical variables so that the Spearman test can be carried out. Meanwhile, for the difference between symptom scores, treatment scores, and combined scores between before and after immunotherapy, the distribution test was used first using the Kolmogorov-Smirnov test, and if the distribution was not normal, the Wilcoxon rank test was used. The value that is considered significant is if the p-value $<0.05$.

\section{Results}

All pediatric patients who came to the pediatric allergy outpatient clinic of Dr. Soetomo General Hospital Surabaya to examine a skin prick test in the period January 1, 2020-December 31, 2021, namely 128 children. Data were taken from patient logbooks at the allergy clinic which consisted of registers of patients undergoing skin prick testing and control logs of immunotherapy patients. There were 128 children who were registered for skin prick testing, 8 were excluded because their medical records were incomplete, and the number of children who met the inclusion criteria was 60 children. The number of samples that can be collected and analyzed in this study is 60 children, this number has exceeded the minimum count of the sample size of 32 children (Figure $1)$. 


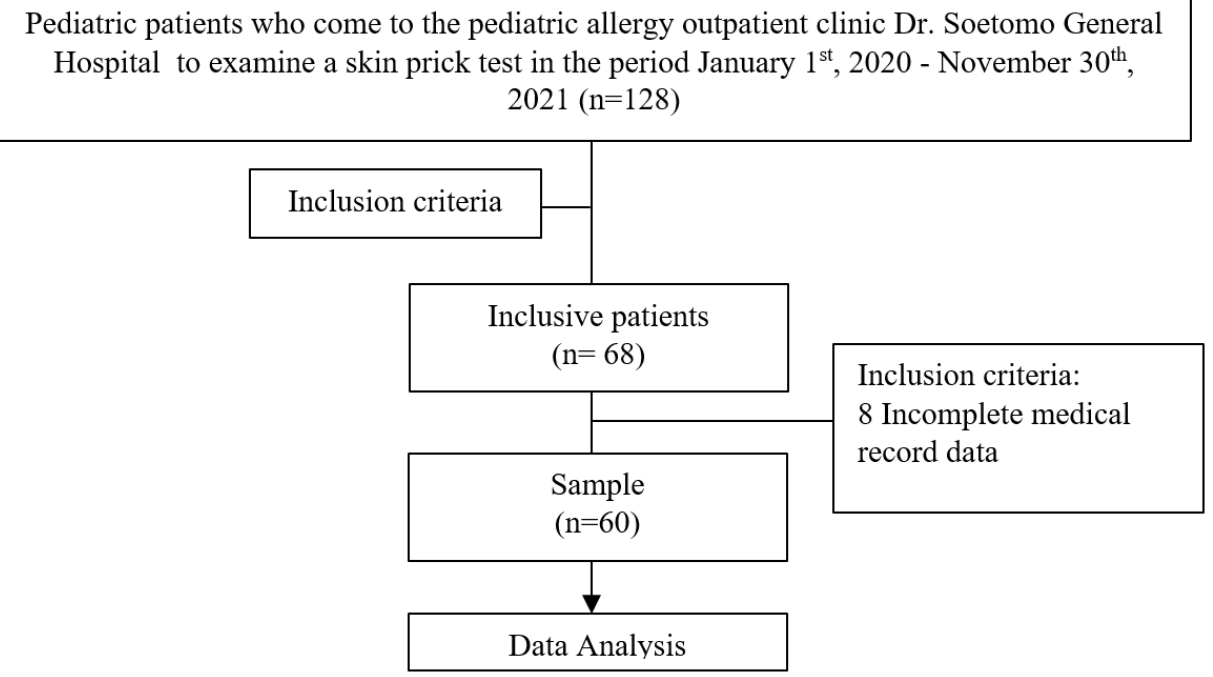

Fig. 1. Research subject flow diagram

There were 60 patients included in this study, consisting of 33 male patients and 27 female patients. Table 1 describes several characteristics including age at the first appearance of HDM-related allergy symptoms, gender, number of nuclear family members with allergies, comorbidities (food allergies, animal dander allergies, asthma), induration diameter of skin prick test results to house dust mite allergens, immunotherapy effectiveness score consisting of symptom score (dSS), treatment score (dMS), and the total score (CSMS) which is a combination of symptom score and treatment score. The total score (CSMS) used to determine the effectiveness of immunotherapy, was taken on two examinations, namely at the time the HDM allergy was diagnosed, then 3 months after immunotherapy.

Table 1. Research principal characteristics

\begin{tabular}{|c|c|}
\hline Characteristic & HDM allergic child $(n=60)$ \\
\hline Age (min-max, mean) & 7 months -13 years ( 5 years 2 months) \\
\hline \multicolumn{2}{|l|}{ Gender } \\
\hline Male & $33(55 \%)$ \\
\hline Female & $27(45 \%)$ \\
\hline $\begin{array}{l}\text { Age when symptoms of HDM appear (min-max; } \\
\text { mean) }\end{array}$ & A month -8 years ( 2 years 3 months) \\
\hline $\begin{array}{l}\text { The number of close family members with allergies } \\
\text { (min-max; mean) }\end{array}$ & $0-3(0.83)$ \\
\hline \multicolumn{2}{|l|}{ Comorbidity } \\
\hline Asthma & $2(3.33 \%)$ \\
\hline food allergy & $41(68.33 \%)$ \\
\hline Animal dander allergy & $20(33.33 \%)$ \\
\hline $\begin{array}{l}\text { Induration diameter of skin pinch test } \\
\text { (min-max, mean) }\end{array}$ & $3-10(4.95) \mathrm{mm}$ \\
\hline
\end{tabular}

\subsection{Effectiveness of Immunotherapy}

The effectiveness of immunotherapy was assessed based on the EAACI/WAO score which was divided into 
symptom score (dSS) and treatment score (dMS). The combination of symptom scores and treatment scores is called the composite score (CSMS). The symptom score was assessed twice before and after at least 3 months of therapy. The symptom scores, treatment scores, and combined scores are shown in Table 2. The score determines the effectiveness of immunotherapy, if the score is getting smaller, there is a change for the better in symptoms and reduced use of drugs in research subjects.

Table 2. Comparative test scores on symptoms, treatment and combination before and after immunotherapy

\begin{tabular}{lll}
\hline Symptoms Score & $\begin{array}{l}\text { Median } \\
\text { (minimum - maximum) }\end{array}$ & $\mathbf{p}^{*}$ \\
\hline dSS score before immunotherapy & $1.00(0.28-2.14)$ & 0.000 \\
dSS score after immunotherapy & $0.42(0.14-1.571)$ & 0.000 \\
dMS score before immunotherapy & $1.00(1.00-3.00)$ & 0.000 \\
dMS score after immunotherapy & $1.00(0-2.00)$ & \\
CSMS score before immunotherapy & $2.14(1.28-5.14)$ & $1.14(0.14-3.00)$ \\
CSMS score after immunotherapy &
\end{tabular}

*wilcoxon signed rank test

In the score variable, a numerical comparative test was performed in two paired groups (symptom, medication, and composite scores before and after immunotherapy) using the Kolmogorov-Smirnov test, the pvalue $=0.001$. The significance value in the data with $\mathrm{p}<0.05$ means that the residual value is not normally distributed, the next test used is the Wilcoxon signed-rank test with $\mathrm{p}=0.000$ which means that there is a significant difference among the dSS, dMS, and CSMS scores before and after therapy.

Significant changes in CSMS scores before and after immunotherapy can be seen in the graph in Figure 2, this means the smaller the CSMS scores after immunotherapy, which reflects a change for the better in the symptoms experienced by patients and the lack of use of drugs for these symptoms, so immunotherapy is considered effective.

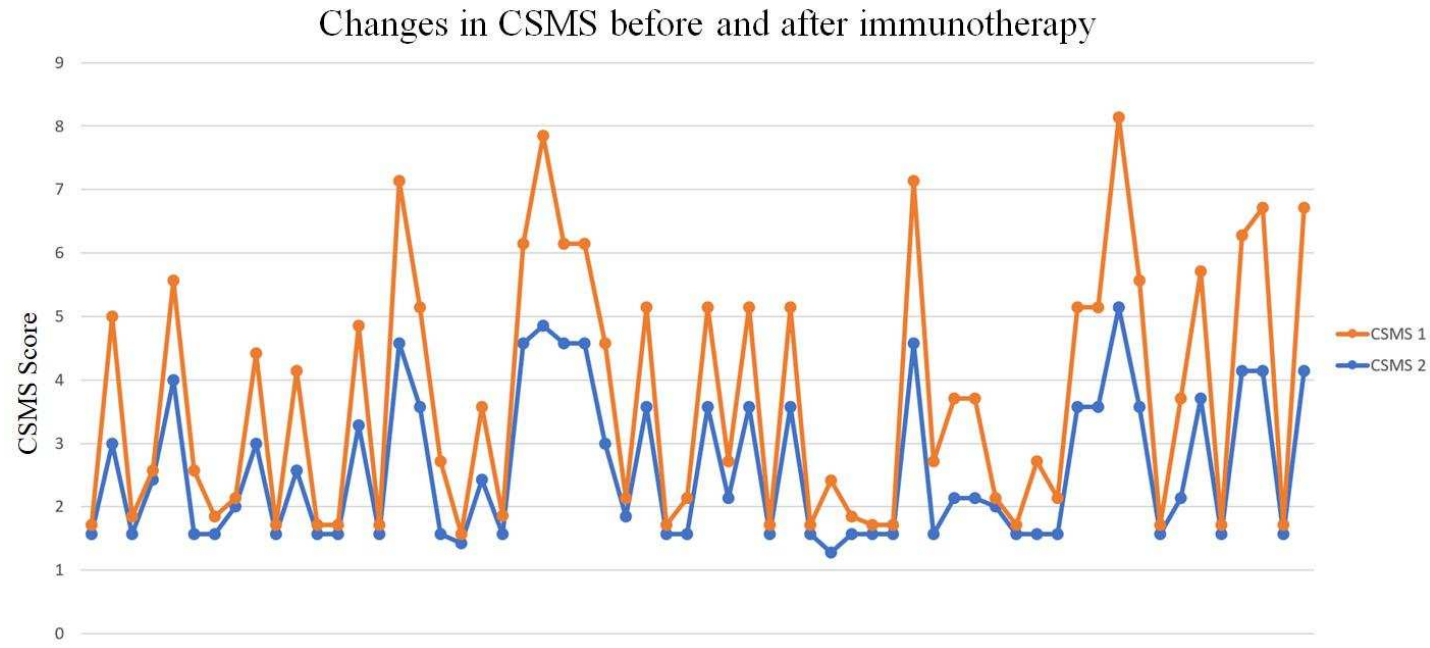

Fig. 2. CSMS change before (CSMS1-orange) and after (CSMS2-blue) immunotherapy

3.2. The correlation of induration diameter of the allergen and CSMS after immunotherapy

The induration diameter of the skin prick test against house dust mite allergens in this research subject was 
found to vary from 3 to $10 \mathrm{~mm}$ (median $4.95 \mathrm{~mm}$ ). The CSMS score after administration of immunotherapy is used to describe the effectiveness of immunotherapy because it is a combination of symptom and treatment scores after at least 3 months of immunotherapy. The first test carried out was the normality test of the two variables using the Kolmogorov-Smirnov test, obtained $p=0.000$, then the numerical correlation used next was the Spearman correlation test (numeric-numeric correlative hypothesis test with abnormal distribution).

In the Spearman correlation test between the induration diameter variable and the combined score of CSMS after immunotherapy (Table 3), the p-value $=0.003, r=0.373$, and a positive correlation. The $\mathrm{p}$-value $<0.05$ means that statistically there is a relationship between the induration diameter and the CSMS score after immunotherapy, while the rho (r) value indicates a weak correlation with a positive form of relationship. This means that the higher the $\mathrm{X}$ variable, the higher the $\mathrm{Y}$ variable. The larger the induration diameter, the higher the CSMS score after immunotherapy. Likewise, the smaller the induration diameter, the smaller the CSMS score after immunotherapy, the better the effectiveness of immunotherapy.

Table 3. Correlation of induration diameter to CSMS score after immunotherapy

\begin{tabular}{ll}
\hline \multirow{2}{*}{$\begin{array}{l}\text { Induration diameter of skin prick test for house dust mite } \\
\text { allergen }\end{array}$} & \begin{tabular}{l} 
CSMS Score \\
\cline { 2 - 2 }
\end{tabular} \\
$\begin{array}{ll}\mathrm{r}=0,373 * \\
\mathrm{n}=60,003\end{array}$ \\
\hline Spearman correlation test &
\end{tabular}

Several variables may affect the induration diameter of the skin prick test results for house dust mite allergens. These variables were age at the time of the skin prick test, gender, length of illness, nuclear family history of allergies, and other allergy comorbidities, namely food allergies. After the bivariate analysis was performed on all variables (each described in Table 4), no p-value was found below 0.05 (using Fisher's exact test analysis), which means that there is no statistically significant relationship between age at skin prick test, gender, duration of illness, nuclear family history of allergies, and comorbidity of food allergies, with the diameter of the induration of the skin prick test results against house dust mite allergens.

Table 4. Variables that affect the induration diameter of skin prick test results

\begin{tabular}{|c|c|c|c|c|c|c|c|c|c|}
\hline \multirow[t]{2}{*}{ Variable } & \multirow[t]{2}{*}{ Characteristic } & \multicolumn{2}{|c|}{$\begin{array}{l}\text { Induration } \\
\text { diameter } \\
\text { 3-6 mm }\end{array}$} & \multicolumn{2}{|c|}{$\begin{array}{l}\text { Induration } \\
\text { diameter } \\
\text { 7-10 mm }\end{array}$} & \multirow[t]{2}{*}{$\begin{array}{l}\text { (Fisher's } \\
\text { Exact test) } \\
\text { P value }\end{array}$} & \multirow[t]{2}{*}{ OR } & \multicolumn{2}{|l|}{ IK } \\
\hline & & $\mathbf{n}$ & $\%$ & n & $\%$ & & & Min & Max \\
\hline \multirow[t]{2}{*}{ Age } & $1 .<5$ years & 28 & $53.8 \%$ & 2 & $25 \%$ & 0.254 & 3.5 & 0.645 & 18.980 \\
\hline & 2.> 5 years & 24 & $46.2 \%$ & 6 & $75 \%$ & & & & \\
\hline \multirow[t]{2}{*}{ Gender } & 1. Male & 29 & $55.8 \%$ & 5 & $62.5 \%$ & 1.00 & 0.757 & 0.163 & 3.502 \\
\hline & 2. Female & 23 & $44.2 \%$ & 3 & $37.5 \%$ & & & & \\
\hline \multirow[t]{2}{*}{ Sick duration } & $1 .<2$ years & 15 & $28.8 \%$ & 2 & $25 \%$ & 1.00 & 1.216 & 0.220 & 6.718 \\
\hline & 2. $>2$ years & 37 & $71.2 \%$ & 6 & $75 \%$ & & & & \\
\hline Close family & 1. yes & 37 & $71.2 \%$ & 4 & $50.0 \%$ & 0.249 & 2.467 & 0.545 & 11.168 \\
\hline with allergies & 2. no & 15 & $28.8 \%$ & 4 & $50.0 \%$ & & & & \\
\hline Food allergy & 1. yes & 34 & $65.4 \%$ & 7 & $34.6 \%$ & 0.416 & 0.270 & 0.031 & 2.368 \\
\hline comorbid & 2. no & 18 & $87.5 \%$ & 1 & $12.5 \%$ & & & & \\
\hline
\end{tabular}

\section{Discussion}

\subsection{Characteristics of research subjects}

In this study, the age of the skin prick test varied between 7 months-13 years. Skin prick testing for aeroallergens should be performed in children over the age of 18 months, only for patients with symptoms and 
a clear history of exposure to allergens, as well as a family history of atopy, to avoid the need for immunotherapy (in this case sublingual immunotherapy) because of the low evidence of efficacy in children aged 2 - 4 years, compared to ages 4 years and over (Larenas-Linnemann et al., 2013).

Moreover, sixty children had positive skin prick test results who had undergone immunotherapy for at least 3 months, and 40 children $(66.66 \%)$ had a history of allergies in the nuclear family. Almost similar to the figures in a study in India regarding skin prick testing on 92 children, in the group sensitive to house dust mites, there were 32 children (65.3\%) with a family history of allergic disease (Doshi and Tripathi, 2016). In addition, the most comorbidities were food allergies with 41 children $(68.33 \%)$, then 20 children with animal dander allergy (33.33\%), and 2 asthmatics (3.33\%). Patients who are consulted by an allergist for allergy testing to house dust mites generally have a moderate to severe disease profile, with high levels of polysensitization and potentially multiple allergies (Demoly et al., 2020). In France, in a retrospective survey of 1289 house dust mite allergy patients receiving immunotherapy, $62.5 \%$ of patients had polysensitization, and $50 \%$ of patients had asthma (Trebuchon et al., 2012). Similarly, in a prospective, cross-sectional, multicenter study of 1212 houses dust mite allergy in France from 2013 to 2014, there were 57.5\% of patients had polysensitization and 42\% had asthma (Demoly et al., 2016). The presence of more frequent asthma was also confirmed by a study in Italy with immunotherapy, with an asthma prevalence of $41 \%$ (Ciprandi et al., 2017).

\subsection{Induration diameter of the skin prick test}

In this study, the size of the induration diameter of the skin prick test varied from $3 \mathrm{~mm}$ to $10 \mathrm{~mm}$ (median $4.95 \mathrm{~mm}$ ). The positive result of the skin prick test used in this study was $3 \mathrm{~mm}$. A skin reaction was considered positive if the area of induration was $7 \mathrm{~mm}^{2}$ or more, which corresponds to a diameter range of $3 \mathrm{~mm}$ (Oppenheimer and Nelson, 2006). The definition of a positive test is a positive reaction that appears as a raised bump with surrounding erythema. This test is described as a bump that is the same size as or larger than the histamine control; histamine usually produces a lump at least $3 \mathrm{~mm}$ in diameter. Generally greater than negative controls, and is considered a positive test threshold. Any reaction that was $3 \mathrm{~mm}$ from the negative control was considered positive for sensitivity. The size of the bumps is not related to the severity of sensitivity to specific allergens (Rengganis, 2018).

Several confounding variables were determined that might affect the induration of the results of the prick test for house dust mite allergy, namely gender, age at the time of the skin prick test, duration of illness, nuclear family history of allergies, and other comorbid allergies, namely food allergies. In statistical analysis, each of these variables was analyzed against the induration diameter of the skin prick test results, and the results were not found to be related.

In this study, gender was not associated with the induration diameter of the skin prick test for house dust mite allergens (Fisher's exact test, $\mathrm{p}=1.00$ ). A study in northern Italy involving 620 subjects (mean age 23.89 years) for the skin prick test found that older age and male sex were associated with higher responses to histamine $(r=0.3408, p<0.0001)$ (Bordignon and Burastero, 2006). In this study, the age variable at the time of the skin prick test was divided into two groups, specifically $<2$ years of age and over two years of age. There was no relationship between age at skin prick test and induration diameter (Fisher's exact test, $\mathrm{p}=1.00$ ). In contrast to the theory which states that skin reactivity varies with age, it was found that children under two years of age had a less reactive pinch test result than adults. The prevalence of positive skin test results increases through the second decade and begins to decline slowly over the age of 60 years. In children with allergic manifestations, however, skin reactivity is similar from one year of age to puberty. However, skin prick test can be used in infants aged 1 month, with high reliability, usually, the area of erythema is larger than the induration reaction (Antunes et al., 2009). The cumulative incidence of allergic manifestations in children in one study showed that males had specific serum IgE positive for any allergen by 2 -year-old $(p=0.007)$ and 5 years $(p=$ 0.039). The skin prick test is more often positive in boys at 5 years of age. The cumulative incidence of allergic disease manifestations was significantly increased between the two evaluations, specifically, the evaluation at 
5 years of age for IgE-associated allergic disease was twice as frequent as the evaluation at 2-year-old (Sandini et al., 2011).

There were 41 patients out of 60 patients with comorbid food allergies (68.33\%). However, statistically, there was no relationship between food allergy and the induration diameter of the skin prick test results for house dust mite allergens. In 2017, a Canadian study found an association between certain food allergies, namely shrimp and sensitization to house dust mite allergens. There were $86(90.5 \%)$ of 95 patients suffering from shrimp allergy, with a positive skin prick test and patients with a skin prick test induration diameter greater than $5 \mathrm{~mm}$. This condition has a risk of 5.31 times $(\mathrm{p}=0.008)$ to have an induration diameter longer than $5 \mathrm{~mm}$. Based on the protein homology theory, individuals with allergies to house dust mites are considered sensitive to the tropomyosin component of house dust mites, so cross-reactivity can occur (Rosenfield et al., 2017).

\subsection{Effectiveness of immunotherapy based on EAACI/WAO score}

In this study, the effectiveness of immunotherapy was assessed based on the EAACI/WAO score, which was divided into symptom score (dSS) and treatment score (dMS). The combination of the symptom score and the treatment score is called the composite score. The symptom score was assessed twice before and after at least three months of therapy. The score determines the effectiveness of immunotherapy, if the score is getting smaller, there is a change for the better in symptoms and use of drugs in research subjects.

There is no universally accepted system for measuring clinical symptom improvement after allergen-specific immunotherapy. The guidelines for allergen-specific immunotherapy in IgE-mediated allergic disease were issued in 2014, stating that clinical immunotherapy effectiveness is measured using scores that vary as primary and secondary outcomes. The European Medicines Agency (EMA) assigned a combined symptom score and treatment as the primary outcome. Harmonization of clinical outcomes using the CSMS score recommended by the EAACI resulted in a comparison of results from various studies (Pfaar et al., 2014).

Allergen-specific immunotherapy generally measures clinical symptoms with a 4-point rating scale. A score of 0 indicates no symptoms; 1 is a mild symptom (obvious, but minimal/not bothersome, easily tolerated); 2 states moderate symptoms (certain awareness that symptoms are bothersome but tolerable); 3 indicates severe symptoms (symptoms difficult to relieve, causing disturbances in activities of daily living and/or sleep). This measurement is very simple and easy to apply by the Food and Drug Administration (FDA) and EMA. This rating scale is calculated based on the mean TSS score of six to eight patient symptoms. Symptoms assessed consisted of nasal symptoms which included itchy nose, sneezing, rhinorrhea, and nasal congestion; conjunctival symptoms which include red/itchy eyes and watery eyes. Chest and shortness of breath symptoms, cough, and wheezing should also be considered in patients presenting with lower airway symptoms. Symptoms should be recorded by the patient on a diary card. Mean total symptoms (daily, weekly, and monthly mean) were calculated to reflect the true clinical symptom burden (Canonica et al., 2007; Pfaar et al., 2014).

The effectiveness of immunotherapy was assessed after the subject received immunotherapy for at least 3 months, the effectiveness of immunotherapy was assessed based on changes in the value of the symptom score, treatment, or a combination of the two. In this study, there were significant changes in symptom scores $(\mathrm{p}=$ $0.001)$, treatment scores $(\mathrm{p}=0.000)$, and combined scores $(\mathrm{p}=0.000)$ at the end of the 3rd month of immunotherapy. This is also consistent with the results of a study in China on 119 pediatric patients who received subcutaneous immunotherapy for 2 years, concluding that the effectiveness of immunotherapy in the second year of subcutaneous immunotherapy can be predicted by changes in the value of the symptom score at month 4 to determine the need for long-term immunotherapy. The effectiveness of immunotherapy was defined as the reduction of the mean symptom score (dSS) at the start of immunotherapy to the mean at the end of the second year of immunotherapy (Liu et al., 2020).

A cohort study in Istanbul Turkey (2001-2015), evaluated the effectiveness of subcutaneous immunotherapy using changes in the induration diameter of the skin prick test and symptom scores. The symptom score used consisted of 6 symptoms, namely nasal congestion, runny nose, nasal itching, sneezing, eye discomfort, and 
headache. Each on a scale of 0-3 ( $0=$ no symptoms, score $0=$ no symptoms; $1=$ mild symptoms (obvious, but feels minimal / not bothersome, easily tolerated); $2=$ moderate symptoms (certain awareness that there are symptoms) disturbing but tolerable symptoms); 3 = severe symptoms (symptoms difficult to relieve, causing disturbances in activities of daily living and/or sleep (Sahin et al., 2017). A meta-analysis study in 2013 evaluated 17 clinical trials For the effectiveness of immunotherapy with seasonal allergic rhinitis, there was a decrease in symptom score ( $p<0.00001$ in all 17 studies $)$, change in treatment score $(\mathrm{p}<0.0001$ in 16 studies), and combined score ( $\mathrm{p}<0.00001$ in 8 studies), as well as quality of life ( $p<0.00001$ in 8 studies) (Dretzke et al., 2013).

\subsection{Diameter of skin prick test induration and effectiveness of immunotherapy}

There is a positive relationship between the induration diameter of the skin prick test on house dust mite allergens and the effectiveness of immunotherapy ( immunotherapy was assessed at least 3 months after undergoing immunotherapy, using the EAACI/WAO score. Statistically, this means that there is a relationship between the induration diameter and the CSMS score after immunotherapy, while the rho (r) value indicates a weak correlation with a positive relationship. This means that the higher the $\mathrm{X}$ variable, the higher the $\mathrm{Y}$ variable. The larger the induration diameter, the higher the CSMS score after immunotherapy. Likewise, the smaller the induration diameter, the smaller the CSMS score after immunotherapy. The smaller diameter of the induration of the skin prick test for house dust mite allergens is a more effective predictor of immunotherapy, so it can be used as educational material for parents for adherence to long-term immunotherapy.

Research on 65 children with allergic asthma in 2019 assessed the effectiveness of immunotherapy based on several parameters, one of which was the induration diameter of the skin prick test results before and after immunotherapy. Effective immunotherapy was in the controlled and partially controlled group of asthma, while ineffective immunotherapy was asthma that was declared uncontrolled based on clinical and laboratory parameters after 3 months of subcutaneous immunotherapy. At the end of the 3rd month (initial phase) there was an improvement in symptoms in $73.8 \%$ of the subjects. The clinical outcome was also statistically associated with the number of eosinophils, decreased levels of IL-10 and IFN- $\gamma$, increased amount of IL-4, and smaller skin prick test induration diameter against Der $\mathrm{p} 1(\mathrm{p}=0.000)$ and Der $\mathrm{p}$. $\mathrm{f} 1(\mathrm{p}=0.000)$ compared to diameter before immunotherapy (Endaryanto, 2019). This is related to the theory that the size of the induration diameter of the skin prick test for Der $\mathrm{p} 1$ and Der $\mathrm{f} 1$ represents the patient's reactivity to house dust mite allergens, which are caused by allergen-specific IgE (Fujita et al., 2012).

There were 26 study subjects aged 23-42 years with allergic rhinitis in Istanbul, Turkey, who received subcutaneous immunotherapy, had a significantly lower change in symptom scores after 3 years of follow-up $(\mathrm{p}<0.0175)$. The effectiveness of immunotherapy in this study was assessed based on the induration diameter of the skin prick test results against house dust mites (Dermatophagoides pteronysinnus and Dermatophagoides farinae) and symptom scores before and after subcutaneous immunotherapy 3 years and 10 years, there were statistically significant changes based on the Friedman test with p-value $=0.000$. The induration diameter of the skin prick test (skin prick test positivity) has decreased in the last decade, even though immunotherapy was only given for 3 years. In other words, even though immunotherapy has been discontinued the positive effects of allergen-specific immunotherapy continue (Sahin et al., 2017).

\section{Conclusions}

In summary, the induration diameter of the skin prick test for house dust mite allergens was not affected by age, gender, length of illness, number of nuclear families with allergic diseases, and comorbidities of other allergic diseases. There is a relationship between the induration diameter of the skin prick test on house dust mite allergens and the effectiveness of immunotherapy. The induration diameter of the skin prick test for house dust 
mite allergens can be used as a predictor of the effectiveness of subcutaneous immunotherapy in children with house dust mite allergy. It is advisable to conduct further research using a prospective cohort method.

\section{Acknowledgements}

The authors thank the Dr. Soetomo General Hospital, Surabaya Indonesia for providing the research facilities.

\section{References}

Antunes, J., Borrego, L., Romeira, A. and Pinto, P., 2009. Skin prick tests and allergy diagnosis. Allergol Immunopathol (Madr) 37, p. 155-64.

Bordignon, V. and Burastero, S. E., 2006. Age, gender and reactivity to allergens independently influence skin reactivity to histamine. J Investig Allergol Clin Immunol 16, p. 129-35.

Bousquet, J., Pfaar, O., Togias, A., Schünemann, H. J., Ansotegui, I., Papadopoulos, N. G., Tsiligianni, I., Agache, I., Anto, J. M., Bachert, C., Bedbrook, A., Bergmann, K. C., Bosnic-Anticevich, S., Bosse, I., Brozek, J., Calderon, M. A., Canonica, G. W., Caraballo, L., Cardona, V., Casale, T., Cecchi, L., Chu, D., Costa, E., Cruz, A. A., Czarlewski, W., Durham, S. R., Du Toit, G., Dykewicz, M., Ebisawa, M., Fauquert, J. L., Fernandez-Rivas, M., Fokkens, W. J., Fonseca, J., Fontaine, J. F., Gerth van Wijk, R., Haahtela, T., Halken, S., Hellings, P. W., Ierodiakonou, D., Iinuma, T., Ivancevich, J. C., Jacobsen, L., Jutel, M., Kaidashev, I., Khaitov, M., Kalayci, O., Kleine Tebbe, J., Klimek, L., Kowalski, M. L., Kuna, P., Kvedariene, V., La Grutta, S., Larenas-Linemann, D., Lau, S., Laune, D., Le, L., Lodrup Carlsen, K., Lourenço, O., Malling, H. J., Marien, G., Menditto, E., Mercier, G., Mullol, J., Muraro, A., O'Hehir, R., Okamoto, Y., Pajno, G. B., Park, H. S., Panzner, P., Passalacqua, G., Pham-Thi, N., Roberts, G., Pawankar, R., Rolland, C., Rosario, N., Ryan, D., Samolinski, B., Sanchez-Borges, M., Scadding, G., Shamji, M. H., Sheikh, A., Sturm, G. J., Todo Bom, A., Toppila-Salmi, S., ValentinRostan, M., Valiulis, A., Valovirta, E., Ventura, M. T., Wahn, U., Walker, S., Wallace, D., Waserman, S., Yorgancioglu, A. and Zuberbier, T., 2019. 2019 ARIA Care pathways for allergen immunotherapy. Allergy 74, p. 2087-2102.

Calderón, M. A., Kleine-Tebbe, J., Linneberg, A., De Blay, F., de Rojas, D. H. F., Virchow, J. C. and Demoly, P., 2015. House dust mite respiratory allergy: an overview of current therapeutic strategies. The Journal of Allergy and Clinical Immunology: In Practice 3, p. 843-855.

Canonica, G. W., Baena-Cagnani, C. E., Bousquet, J., Bousquet, P. J., Lockey, R. F., Malling, H. J., Passalacqua, G., Potter, P. and Valovirta, E., 2007. Recommendations for standardization of clinical trials with Allergen Specific Immunotherapy for respiratory allergy. A statement of a World Allergy Organization (WAO) taskforce. Allergy 62, p. 317-24.

Cheng, L., Chen, J., Fu, Q., He, S., Li, H., Liu, Z., Tan, G., Tao, Z., Wang, D., Wen, W., Xu, R., Xu, Y., Yang, Q., Zhang, C., Zhang, G., Zhang, R., Zhang, Y., Zhou, B., Zhu, D., Chen, L., Cui, X., Deng, Y., Guo, Z., Huang, Z., Huang, Z., Li, H., Li, J., Li, W., Li, Y., Xi, L., Lou, H., Lu, M., Ouyang, Y., Shi, W., Tao, X., Tian, H., Wang, C., Wang, M., Wang, N., Wang, X., Xie, H., Yu, S., Zhao, R., Zheng, M., Zhou, H., Zhu, L. and Zhang, L., 2018. Chinese Society of Allergy Guidelines for Diagnosis and 
Treatment of Allergic Rhinitis. Allergy Asthma Immunol Res 10, p. 300-353.

Ciprandi, G., Natoli, V., Puccinelli, P. and Incorvaia, C., 2017. Allergic rhinitis: the eligible candidate to mite immunotherapy in the real world. Allergy Asthma Clin Immunol 13, p. 11.

Demoly, P., Broué-Chabbert, A., Wessel, F. and Chartier, A., 2016. Severity and disease control before house dust mite immunotherapy initiation: ANTARES a French observational survey. Allergy Asthma Clin Immunol 12, p. 13.

Demoly, P., Matucci, A., Rossi, O. and Vidal, C., 2020. The disease burden in patients with respiratory allergies induced by house dust mites: a year-long observational survey in three European countries. Clin Transl Allergy 10, p. 27.

Di Lorenzo, G., Mansueto, P., Pacor, M. L., Rizzo, M., Castello, F., Martinelli, N., Ditta, V., Lo Bianco, C., Leto-Barone, M. S., D'Alcamo, A., Di Fede, G., Rini, G. B. and Ditto, A. M., 2009. Evaluation of serum s-IgE/total IgE ratio in predicting clinical response to allergen-specific immunotherapy. Journal of Allergy and Clinical Immunology 123, p. 1103-10, 1110.e1-4.

Doshi, A. and Tripathi, D. M., 2016. Early House Dust Mite Sensitivity in Mumbai Children. Indian Journal of Pediatrics 83 , p. 386-90.

Dretzke, J., Meadows, A., Novielli, N., Huissoon, A., Fry-Smith, A. and Meads, C., 2013. Subcutaneous and sublingual immunotherapy for seasonal allergic rhinitis: a systematic review and indirect comparison. Journal of Allergy and Clinical Immunology 131, p. 1361-6.

Endaryanto, A., 2019. The build-up phase outcome of subcutaneous immunotherapy for pediatric allergic asthma: A retrospective cohort study from Surabaya, Indonesia. Bali Medical Journal; Vol 8, No 1 (2019): (Available online 1 April 2019).

Endaryanto, A., 2020. Memahami dan mengurai kompleksitas manajemen alergi pada anak Indonesia, 1 ed., Surabaya: Airlangga University Press.

Erekosima, N., Suarez-Cuervo, C., Ramanathan, M., Kim, J. M., Chelladurai, Y., Segal, J. B. and Lin, S. Y., 2014. Effectiveness of subcutaneous immunotherapy for allergic rhinoconjunctivitis and asthma: a systematic review. Laryngoscope 124, p. 616-27.

Frew, A. J., Ljørring, C., Wolf, H., Wüstenberg, E., Durham, S. R., Corrigan, C. J., Powell, R. J. and Pfaar, O., 2018. UK Immunotherapy Study: Reanalysis by a combined symptom and medication score. Journal of Allergy and Clinical Immunology 142, p. 1998-1999.e3.

Fujita, H., Soyka, M. B., Akdis, M. and Akdis, C. A., 2012. Mechanisms of allergen-specific immunotherapy. Clinical and translational allergy 2, p. 2.

Heinzerling, L., Mari, A., Bergmann, K. C., Bresciani, M., Burbach, G., Darsow, U., Durham, S., Fokkens, W., Gjomarkaj, M., Haahtela, T., Bom, A. T., Wöhrl, S., Maibach, H. and Lockey, R., 2013. The skin prick test - European standards. Clin Transl Allergy 3, p. 3.

Larenas-Linnemann, D., Blaiss, M., Van Bever, H. P., Compalati, E. and Baena-Cagnani, C. E., 2013. Pediatric 
sublingual immunotherapy efficacy: evidence analysis, 2009-2012. Ann Allergy Asthma Immunol 110, p. 402-415.e9.

Liu, Z., Lu, H., Feng, X., Hu, L., Wang, J. and Yu, H., 2020. Predictive methods for efficacy of house dust mite subcutaneous immunotherapy in allergic rhinitis patients: a prospective study in a Chinese population. Int Forum Allergy Rhinol 10, p. 314-319.

Moustaki, M., Loukou, I., Tsabouri, S. and Douros, K., 2017. The Role of Sensitization to Allergen in Asthma Prediction and Prevention. Frontiers in pediatrics 5, p. 166-166.

Oppenheimer, J. and Nelson, H. S., 2006. Skin testing: a survey of allergists. Ann Allergy Asthma Immunol 96, p. 19-23.

Pfaar, O., Bachert, C., Bufe, A., Buhl, R., Ebner, C., Eng, P., Friedrichs, F., Fuchs, T., Hamelmann, E., HartwigBade, D., Hering, T., Huttegger, I., Jung, K., Klimek, L., Kopp, M. V., Merk, H., Rabe, U., Saloga, J., Schmid-Grendelmeier, P., Schuster, A., Schwerk, N., Sitter, H., Umpfenbach, U., Wedi, B., Wöhrl, S., Worm, M., Kleine-Tebbe, J., Kaul, S. and Schwalfenberg, A., 2014. Guideline on allergen-specific immunotherapy in IgE-mediated allergic diseases: S2k Guideline of the German Society for Allergology and Clinical Immunology (DGAKI), the Society for Pediatric Allergy and Environmental Medicine (GPA), the Medical Association of German Allergologists (AeDA), the Austrian Society for Allergy and Immunology (ÖGAI), the Swiss Society for Allergy and Immunology (SGAI), the German Society of Dermatology (DDG), the German Society of Oto- Rhino-Laryngology, Head and Neck Surgery (DGHNO-KHC), the German Society of Pediatrics and Adolescent Medicine (DGKJ), the Society for Pediatric Pneumology (GPP), the German Respiratory Society (DGP), the German Association of ENT Surgeons (BV-HNO), the Professional Federation of Paediatricians and Youth Doctors (BVKJ), the Federal Association of Pulmonologists (BDP) and the German Dermatologists Association (BVDD). Allergo J Int 23, p. 282-319.

Rasool, R., Shera, I. A., Nissar, S., Shah, Z. A., Nayak, N., Siddiqi, M. A. and Sameer, A. S., 2013. Role of skin prick test in allergic disorders: a prospective study in kashmiri population in light of review. Indian journal of dermatology 58, p. 12-17.

Rengganis, I., 2018. Skin prick test dalam diagnosis penyakit alergi Jakarta: Badan Penerbit Fakultas Kedokteran Universitas Indonesia.

Rosenfield, L., Tsoulis, M. W., Milio, K., Schnittke, M. and Kim, H., 2017. High rate of house dust mite sensitization in a shrimp allergic southern Ontario population. Allergy Asthma Clin Immunol 13, p. 5.

Sahin, E., Dizdar, D., Dinc, M. E. and Cirik, A. A., 2017. Long-term effects of allergen-specific subcutaneous immunotherapy for house dust mite induced allergic rhinitis. J Laryngol Otol 131, p. 997-1001.

Sandini, U., Kukkonen, A. K., Poussa, T., Sandini, L., Savilahti, E. and Kuitunen, M., 2011. Protective and risk factors for allergic diseases in high-risk children at the ages of two and five years. International Archives of Allergy and Immunology 156, p. 339-48.

Shin, Y. S., Jung, J. W., Park, J. W., Choi, J. H., Kwon, J. W., Lee, S., Kim, J. H., Lee, S. M., Ahn, Y. M. and Han, M. Y., 2019. Clinical Efficacy of Allergen-Specific Immunotherapy from Patient and Physician Perspectives. Yonsei Med J 60, p. 446-453. 
Tham, E. H., Lee, A. J. and Bever, H. V., 2016. Aeroallergen sensitization and allergic disease phenotypes in Asia. Asian Pacific Journal of Allergy \& Immunology 34, p. 181-189.

Trebuchon, F., David, M. and Demoly, P., 2012. Medical Management and Sublingual Immunotherapy Practices in Patients with House Dust Mite-Induced Respiratory Allergy: A Retrospective, Observational Study. International Journal of Immunopathology and Pharmacology 25, p. 193-206.

Yang, L. and Zhu, R., 2017. Immunotherapy of house dust mite allergy. Human vaccines \& immunotherapeutics 13, p. 2390-2396.

Zhong, J., Liu, D.-B., Huang, Z.-Y. and Zhong, J., 2014. Skin Prick Test Reactivity to Aeroallergens in Allergic Rhinitis Children in Guangzhou, Southern China. J Allergy Ther 5, p. 2. 